\title{
Evaluation on the Effect of Regional Development Policy: The Case of Guizhou Province's Catching-up Strategy in China
}

\author{
Baiping Zhang ${ }^{1,2}$ \\ ${ }^{1}$ School of Economy, The Central University of Finance and Economy, Beijing, China \\ ${ }^{2}$ Anshun College, Anshun, Guizhou Province, China \\ Correspondence: Baiping Zhang, School of Economy, The Central University of Finance and Economy, Beijing, \\ China. E-mail: zhbp1969en@163.com
}

Received: October 8, 2021

Accepted: November 15, 2021

Online Published: November 16, 2021

doi:10.5539/jsd.v14n6p97

URL: https://doi.org/10.5539/jsd.v14n6p97

\begin{abstract}
China has been facing the dangerous dilemma of unbalanced regional development as the world does. With the coming of the two centenary goals, facing the peculiar difficulties and present conditions in Guizhou province, the central government of the People's Republic of China made and implemented the catching-up strategy in Guizhou province in 2012. This paper regards implementing catching-up strategy in Guizhou province as a social quasi experiment, chooses 15 middle and western provinces or municipalities to compose control group, applies provincial panel data from 1998 to 2017, and uses synthetic control method to acquire a synthetic Guizhou province which is specified as a counterfactual condition of Guizhou after 2011 to study the economic effects of catching-up strategy quantitatively. The conclusion of positive econometric analysis indicates: from 2011 onward when implementing catching-up strategy, Guizhou Province's growth rate of real GDP is higher than 'the synthetic Guizhou' by 1.4 percent to 3.4 percent. The paper asserts that in comparison with the universal strategy of regional development, practicing targeted catching-up strategy aiming at special region could realize surpassing speedily.
\end{abstract}

Keywords: catching-up strategy, economic growth, Guizhou Province in China, synthetic control method

\section{Introduction}

The dilemma of unbalanced regional development, a threat to human peace, safety and sustainability, had been besetting the governments and researchers since the Industrial Revolution. In response to this situation, the idea of catching-up strategy became consensus. In practice, all the governments implement concrete region-based policies in accordance with their situation of national development.

China has made great progress of development through the strategy of reform and opening-up since 1979, per capita income increasing from 40 dollars to 10,000 dollars. But China's high rapid development enlarged the unbalanced interregional gap among eastern China, central China and western China, as well as within provincial region. China is facing the unbalanced regional development as the world does. In order to cope with this issue, Chinese central government has been carrying out the balanced strategy of interregional development, such as the strategy for large-scale development of western China commenced in 1999, strategy for the rise of central China commenced in 2004, and the strategy for the rejuvenation of Northeast China commenced in 2003. Besides, facing the special situation of underdevelopment in southwest China's Guizhou Province, central government of China carried out the catching-up strategy of latecomer in 2012.

Because every concrete catching-up policy, considered as great and irreversible social experiment, affects the national development significantly, the policy makers and researchers want to know its effect. The classical econometric method to estimate the effects of policy shock on national or regional development was differencein-difference (hereafter DID) model created by Card and Krueger (Card \& Krueger, 1994) who researched the effect of New Jersey's Minimum Wages Act on employment. Liu and Zhao (Liu \& Zhao, 2015) applied DID method to estimate the effect of strategy for large-scale development of western China. Basing on DID idea, Abadie and Gardeazabal (Abadie \& Gardeazabal, 2003) developed a new method called synthetic control method, using other Spanish regions to construct a "Synthetic" Basque County without terrorism as Basque county's counterfactual rather than directly using other Spanish regions without terrorism as comparison group. Synthetic control method gives every comparison sample a rational weight rather than equal weight to generate a weighted 
combination of comparison group chosen to resemble the characteristics of the treated before policy shock. So, synthetic control method improved the idea used to choose the comparison group, making the counterfactual situation more accurate. Typically, applying the synthetic control method, Chinese scholars Yang \& Rong (Yang \& Rong, 2017) evaluated the effects of special strategy for revitalizing the traditional industrial base in northeast China, and, Liu \& Wang (Liu \& Wang, 2018) estimated the effects of free-trade zone on promoting innovative performance with evidence from the Shanghai Free-trade Zone in China. Benefitting from Chinese great reform and development since 1979, economic policies were carried out frequently for industries or special regions, which provides quasi experiments for researchers to evaluate the effects of social and economic policies.

This paper applies synthetic control method to estimate the effect of Guizhou's catching-up strategy of latecomer. The structure of demonstration is as follows: profiles and effects of policies for Guizhou province's catching-up strategy of latecomer, then, dataset and model specification, and then, regression analysis and hypothesis test, last, conclusion.

\section{Profiles and Effects of Policies for Guizhou Province's Catching-up Strategy of Latecomer}

Guizhou province, formed as a provincial region in $1413 \mathrm{AD}$, the Ming Dynasty in Chinese history, is a landlocked region located in the southwest China and has five neighboring provinces. Historically, Guizhou province, as its particular location and Karst landform, i.e., 80 percent of its earth is mountains and hills and only 10 percent is agrarian land, only one province without big plain, is always an underdeveloped region. We could see, from Figure 1 , even by 2017, Guizhou's per capita GDP is 63 percent of the national average.

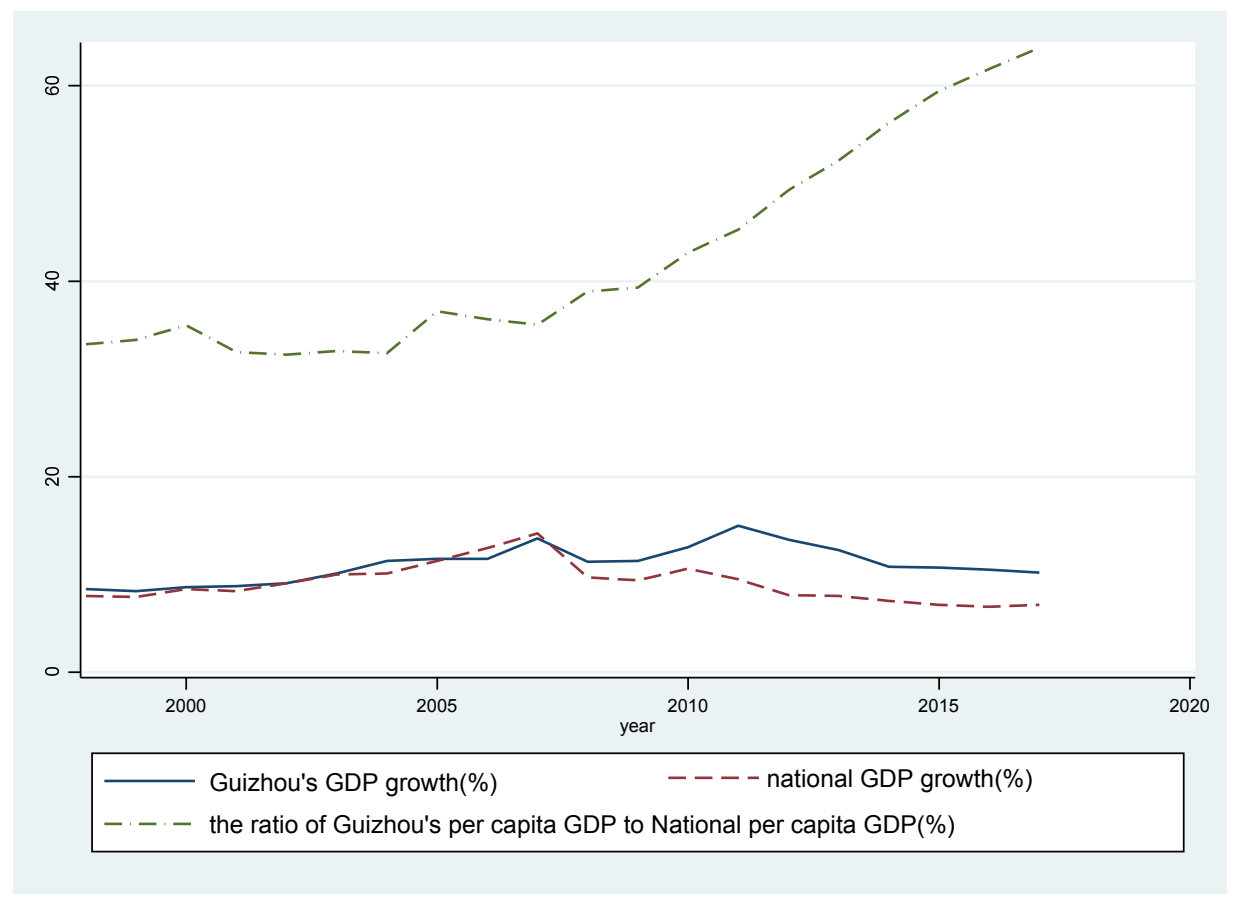

Figure 1. Guizhou province's economic growth in comparison with country

On the road to common prosperity, Guizhou province's current situation has attracted the central government's attention, leading to implement especial place-based regional development policy in 2012 formally, titled the State Council's suggestions on further promoting good and rapid social-economic development in Guizhou province, called as the strategy for catching up in Guizhou province (hereafter the strategy). From 2012 to 2020, the targets of the strategy are as follows: making great progress on the infrastructures, especially in transportation and water resources; effective adjustment on industrial structure, i.e., turning the conditional agriculture into modern agriculture, technological industry and modern service, and basically forming the system of modern industry; restoration and protection of ecological environment; development prior to education; and poverty elimination. The State Council explicitly promised in the document to strengthen the policy support and fiscal investment in all aspects, including investment policy, financial policy, industry policy, land policy, and human capital policy, et al.

Since 2012 when carrying out the strategy for catching up in Guizhou province, central and provincial governments 
have worked together to advance the development of transportation, including air transport, railway transport, and highway transport which could go to every county all the province; meanwhile, local governments at all counties striven to reconstruct the villages with ethnic minority characteristics and train ethnic villagers to improve the quality of tourism services and local tourism appeal. As a result, the annual growth rate of its gross regional product (hereafter GDP) has always exceeded the national economic growth rate (Fig. 1), and the annual growth rate of the ration of its per capita GDP to national per capita GDP is more than 5.9 percent, in contrast to 2.33 percent from 1998 to 2011, entailing decreasing gap in aspects of per capita GDP and income.

Though Guizhou acquired significant development during the last two decades, did the country. So, it is necessary to identify and estimate the effects of the policy for regional development in order to appraise and adjust the strategy timely, that gives researchers a good quasi social experiment.

\section{Control Regions and Indictors}

\subsection{Selecting Comparison Group}

Usually, researchers elect directly other provinces and autonomous regions except Guizhou province as comparison group in China, which leads to estimation bias for the reason of the bigger difference between treated sample and comparison group, such as development gap between eastern and western China, i.e., it is unreasonable to choose east China's provinces as comparisons to Guizhou province. As a response to this and according to empirical application of synthetic control method, the research mainly selects central and west China's provinces and autonomous regions as samples within comparison group, i.e., Shanxi Province, Anhui Province, Henan Province, Jiangxi Province, Hubei Province, Hunan Province, Inner Mongolia Autonomous Region (hereafter Inner Mongolia), Ningxia Hui Autonomous Region (hereafter Ningxia), Xinjiang Autonomous Region (hereafter Xinjiang), Guangxi Zhuang Autonomous Region (hereafter Guangxi), Sichuan Province, Shaanxi Province, Qinghai Province, Gansu Province, and Yunnan Province.

\subsection{Indicators and Variables}

According to Cobb-Douglas productive function, the main indicators affecting local economic growth and social development are gross domestic product, investment, human capital and the ratio of urbanization et al. Macroeconomist highlights the economic growth rate more than other economic indicators discussing decreasing development gap and catching-up strategy, for, under the higher growth rate of economy than developed regions, developing regions could catch up with them. On the other hand, thinking about Guizhou's current situation with the lowest rank in China. As a response to these, the paper selects the growth rate of gross regional product (hereafter GDP) as dependent variable with the shorthand notation 'gdp_rate', and indicators as independent variables as follows: the ratio of investment in fixed assets to GDP with the shorthand notation 'inv_gdp' to measure the effects of investment in fixed assets on local economic growth, the ratio of illiterates over 15 years old to provincial population with the shorthand notation 'ill_rate' to measure the local level of human capital, the ratio of fiscal expenditure to GDP with the shorthand notation 'fis_gdp' to measure the effects of government expenditure on local economy, the ratio of total imports and exports to GDP with the shorthand notation 'trade_gdp' to measure the economic linkage with foreign countries, the ratio of urban employment to the provincial population with the shorthand notation 'urem' to measure the industrial structure, and the number of patent per 100 thousand peoples with shorthand notation 'patent' to reflect the abilities of innovation at the provincial level. All the data used come from China Statistical Yearbook (1998-2017), and the descriptive statistics of variables is in Table 1.

Table 1. The descriptive statistics of variables

\begin{tabular}{lccccc}
\hline Variable & Obs & Mean & Std.Dev. & Min & Max \\
\hline gdp_rate & 320 & 10.71 & 2.737 & 3.100 & 23.80 \\
ill_rate & 320 & 10.18 & 6.161 & 1.780 & 42.92 \\
inv_gdp & 320 & .648 & .267 & .220 & 1.480 \\
fis_gdp & 320 & .226 & .102 & .0500 & .630 \\
trade_gdp & 320 & .0978 & .0466 & .0100 & .390 \\
urem & 320 & .146 & .0526 & .0600 & .380 \\
patent & 320 & 16.40 & 21.20 & 1.140 & 127.1 \\
\hline
\end{tabular}




\section{The Specification of Models and Outcomes}

\subsection{Specifying Econometric Models}

According to Abadie et al (Abadie et al, 2003; 2010; 2015), the regions similar to the treated unit and without event shocks during the time of observation could be considered as controlled units in a country. Let $T_{0}$ be the pre-policy period, $T_{1}$ the post-policy period, and $T=T_{0}+T_{1}$. The core idea of the synthetic control method is how to weight the controlled units to construct a synthesized 'Guizhou' (i.e., counterfactual) reflecting Guizhou's situation without policy shock in the period of $T_{1}$. Let $X_{1}$ be a $(K \times 1)$ vector of pre-policy values of $K$ economic indicators for Guizhou Province in Tab.1, and $X_{0}$ be a $(K \times J)$ matrix which contains the values of the same variables for the $\mathrm{J}$ possible control regions. Let $V$ be a diagonal matrix with nonnegative components. The vector of weights $W^{*}$ is chosen to minimize $\left(X_{1}-X_{0} W\right)^{\prime} V\left(X_{1}-X_{0} W\right)$ subject to $w_{j} \geq 0(j=$ $1,2, \ldots, J)$ and $w_{1}+w_{2}+\cdots+w_{J}=1$, with the values of independents in the period of $T_{0}$. According to Abadie, the best solution of vector $V$ is one. The vector $W^{*}$ defines the combination of control regions which best resembled Guizhou Province in economic growth determinants at the beginning of strategy for catching up (Abadie $\&$ Gardeazabal, 2003). Then, $X_{1}^{*}=X_{0} W^{*}$. After implementing the strategy for catching up in Guizhou Province, the synthetic 'Guizhou' is equal to the 'real Guizhou' without the effects of policy. The outcome of $W^{*}$ shows in the Table 2.

Table 2. The weights of control regions with parametric model

\begin{tabular}{cccccc}
\hline Control region & Weight & $\begin{array}{c}\text { Control } \\
\text { region }\end{array}$ & Weight & $\begin{array}{c}\text { Control } \\
\text { region }\end{array}$ & Weight \\
\hline Shanxi & 0 & Hubei & 0 & Shaanxi & 0 \\
Inner Mongolia & 0 & Hunan & 0 & Gansu & $.343(.5663)$ \\
Anhui & 0 & Guangxi & $0(.1016)$ & Qinghai & .127 \\
Jiangxi & 0 & Sichuan & 0 & Ningxia & 0 \\
Henan & .202 & Yunnan & $.328(.3321)$ & Xinjiang & 0 \\
\hline
\end{tabular}

(Weights running nonparametric model are in parentheses)

Let $Y_{1}$ be a $(T \times 1)$ vector whose elements are the value of the growth rate of GDP for Guizhou Province during T time periods. Let $Y_{0}$ be a $(T \times J)$ matrix which contains the values of the growth rate of GDP for the control regions during the same time. Whereby, using the weights of control regions $W^{*}$, the growth rate of GDP of synthetic 'Guizhou' is as follow: $Y_{1}^{*}=Y_{0} W^{*}$, i.e., gdp_rate $e_{1}^{*}=g d p_{-}$rate $W^{*}$. Theoretically, the more effective $Y_{1}^{*}$ fits the real $Y_{1}$ during the period of $T_{0}$, the better the model estimates during the period of $T_{1}$.

\subsection{Econometric Outcomes}

Figure 2 plots $Y_{1}$ and $Y_{1}^{*}$ for the period 1998-2017 with parametric synthetic control method (Abadie \& Gardeazabal, 2003), and Fig. 3 with non-parametric synthetic control method (Cerulli, 2019), which shows the two curves are very consistent. Table 3 shows the growth rate of real Guizhou Province is higher than its counterfactual 'synthetic guizhou' in detail, especially, the former higher than the latter over 2 percentage in 2015, 2016 and 2017, testifying the significant effect of catching-up strategy on Guizhou Province from 2011 to 2017. 


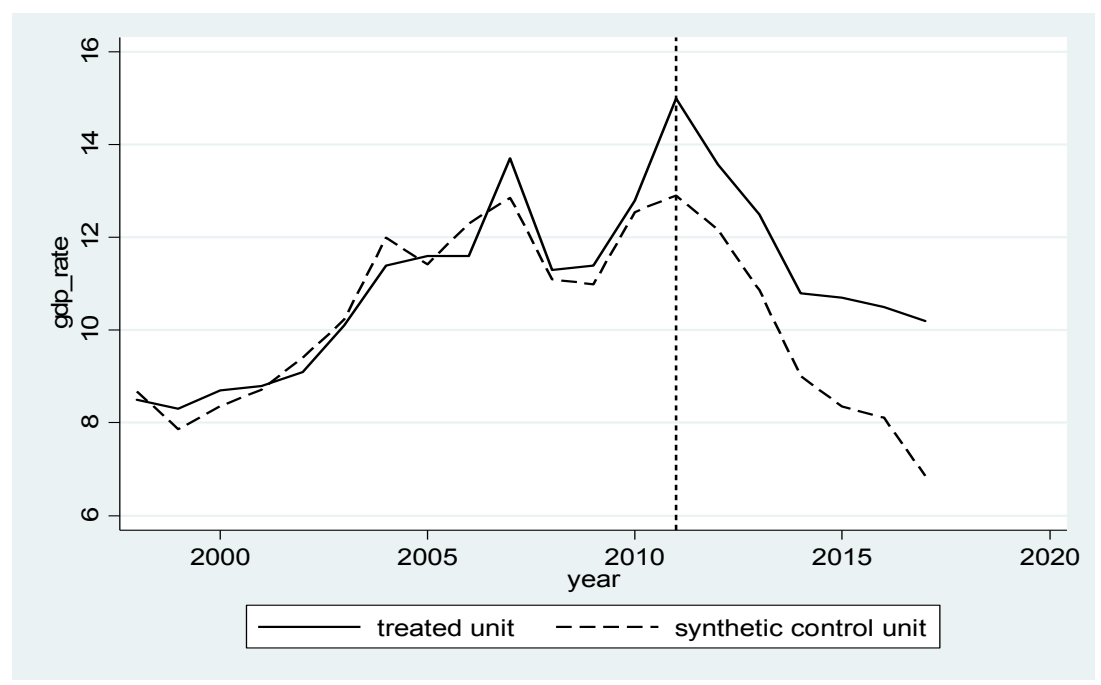

Figure 2. The growth rate of GDP for Guizhou Province, parametric model

Table 3. The comparison of growth rate between real Guizhou Province and 'synthetic guizhou' from 2011 to 2017 (\%)

\begin{tabular}{cccccccc}
\hline & 2011 & 2012 & 2013 & 2014 & 2015 & 2016 & 2017 \\
\hline Real Guizhou & 15 & 13.5 & 12.5 & 10.8 & 10.7 & 10.5 & 10.2 \\
Synthetic Guizhou & 12.9 & 12.1 & 10.8 & 9.0 & 8.3 & 8.1 & 6.8 \\
Effects of strategy & 2.1 & 1.4 & 1.7 & 1.8 & 2.4 & 2.4 & 3.4 \\
\hline
\end{tabular}

\section{Testing}

Though the estimator of the effect of strategy for catching up on Guizhou Province is significant, the statistical test could further guarantee the power of estimation. Robust test and placebo test are carried out as follows.

\subsection{The Robust Test}

This research carries out the robust test by changing the units in the control sample to reconstruct a new 'synthetic guizhou' to view whether the findings is similar to the preceding outcome. Specifical results are showed in Figure 4: (a) representing ruling out Qinghai Province, weight 0.127 showed in the Table 2, and (b) just selecting Henan Province, Yunnan Province and Gansu Province as units in control sample to carry out synthetic control analysis. All these findings are almost consistent. 


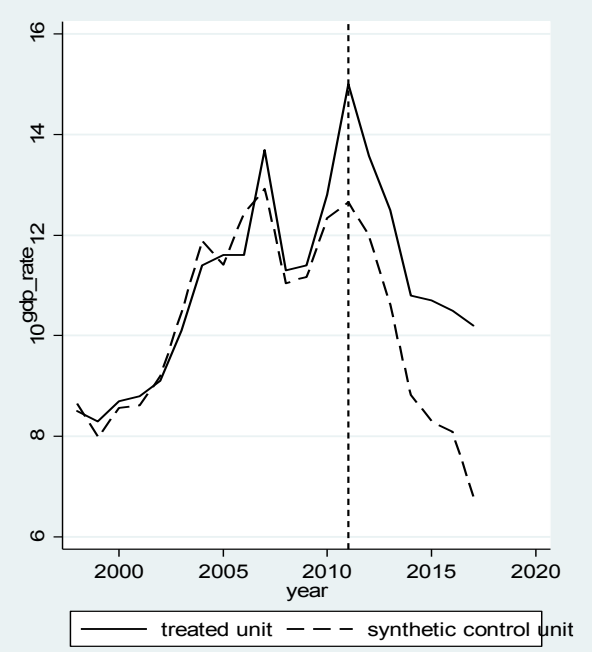

(a)

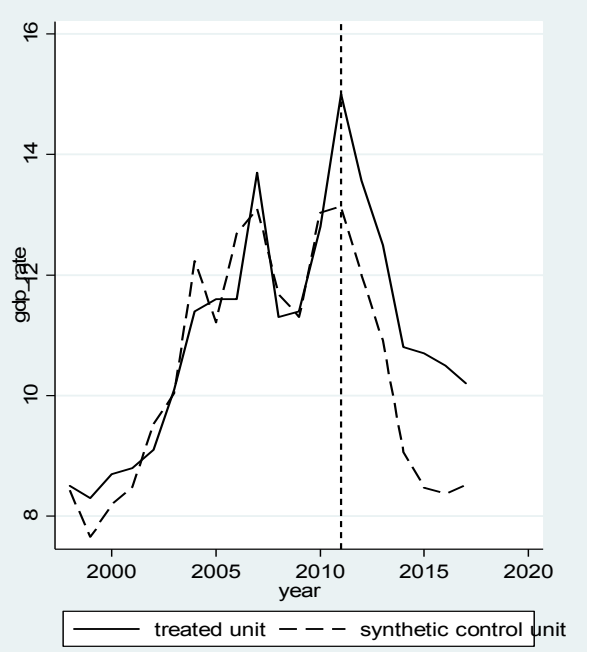

(b)

Figure 4. Results changing the units in control sample

\subsection{The Placebo Test}

Gansu Province, the highest weight to 'the synthetic guizhou' in Table 2, ceteris paribus, is selected as treated unit replacing Guizhou Province to carry out placebo test. For Gansu did not obtain any especial region-based policies, its real growth rate curve is synchronous to the counterfactual curve, or these two curves twine each other, as showed in Figure 5.

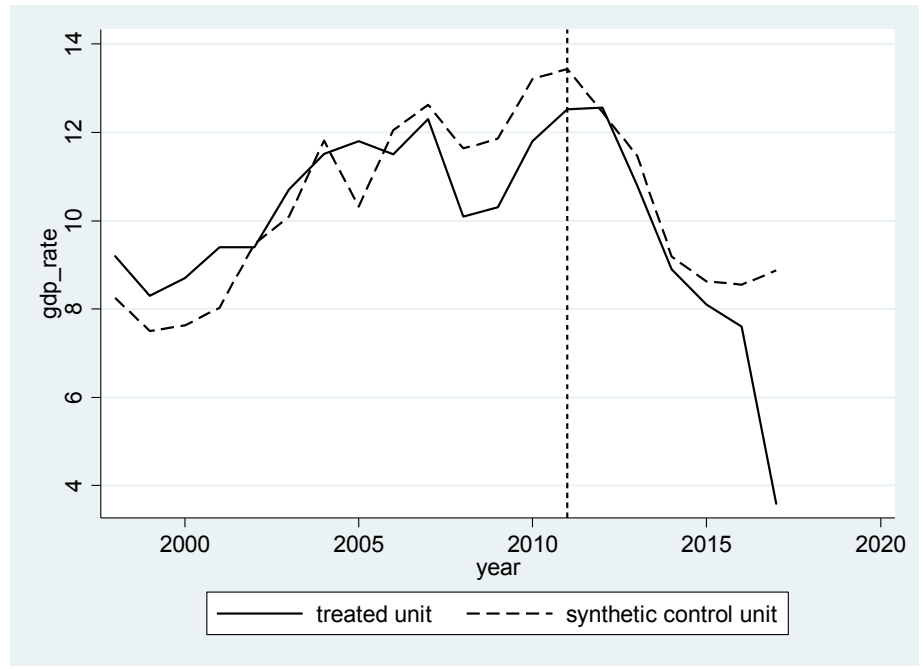

Figure 5. Synthetic control analysis for Gansu Province as treated unit

These tests mean that the estimation applying synthetic control method to the effects of catching-up strategy on Guizhou Province is convincing.

\section{Discussion and Conclusion}

Economist asserted that under-developing region could not realize catching up until outer support was imposed on it.

The support policies for catching up in Guizhou Province is mainly to forge ahead with the transport infrastructure and increase investment. In 2019, Guizhou Province realized the linkage between counties by highway roads, the only one province all over the country, testified from the investment in fixed assets in Guizhou Province. Figure 6 
shows the fact that the ratio of Guizhou Province's investment in fixed assets to its GDP has grown linearly from 2009, and what is more, over 100 percent from 2015 to 2017, and of course, higher than the national level.

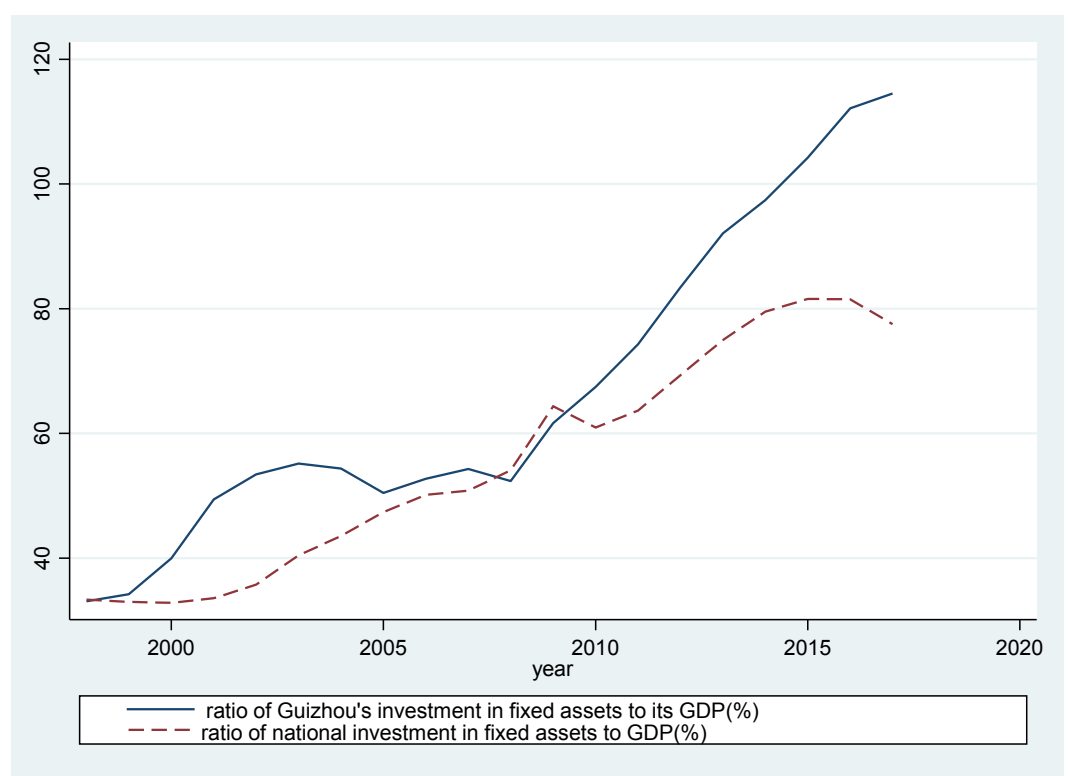

Figure 6. The comparison of investment between Guizhou Province and the country

As a response to continuous improvement in transport infrastructure, potential tourists transform their tourism desires to Guizhou province into action, and the quality natural tourism resources and authentic cultural resources realize the resource rents in Guizhou province. Figure 7 shows the ratio of tourism receipts to GDP in Guizhou province from 1998 to 2017, always higher than the national level which is below 7 percent. Tourism industry contributes significantly to economic growth in Guizhou province.

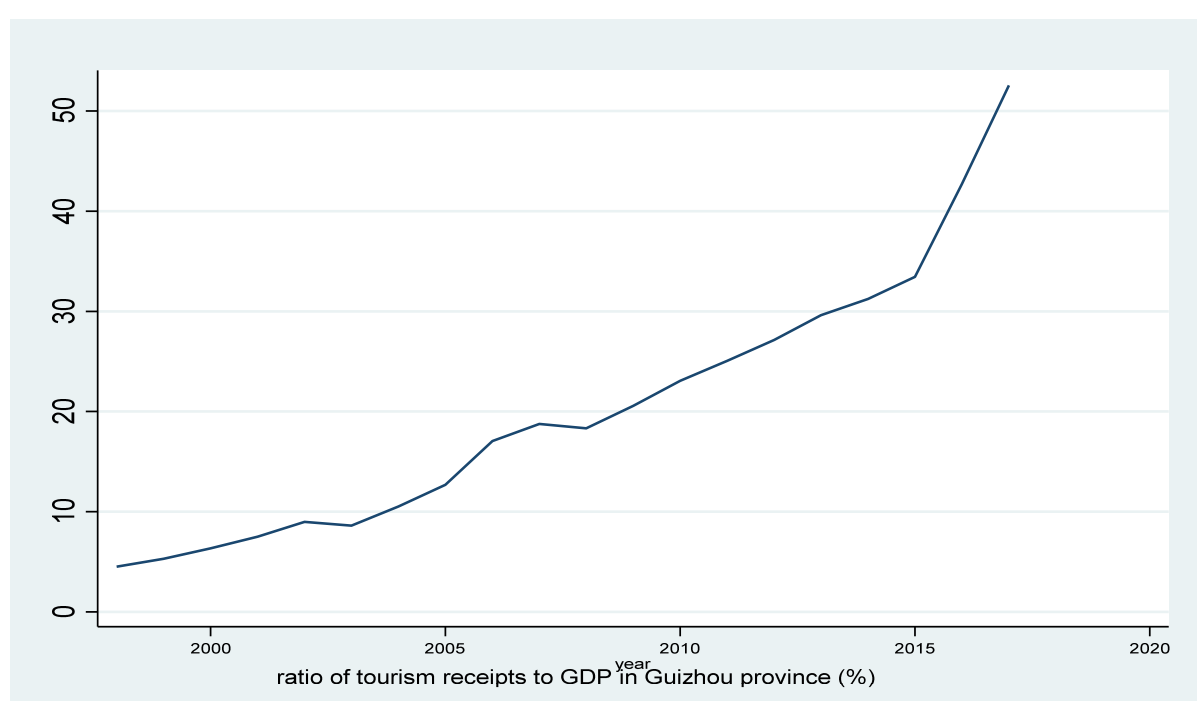

Figure 7. The ratio of tourism receipts to GDP in Guizhou province

So, in facing especially under-developing region within a country, and additionally, allowing for the differences among administrative regions, simultaneous multiregional support policies for economic development usually seem to be low effective or ineffective. Region-based, or province-specific support policies for catching up are testified effectively as its orientation to concrete problems, i.e., there is always an eligible policy for catching up for special region. 


\section{References}

Abadie, A., \& Javier, G. (2003). The Economic costs of conflict: A case study of the Basque Country. The American Economic Review, (3), 113-132. https://doi.org/10.1257/000282803321455188

Abadie, A., Alexis, D., \& Jens, H. (2010). Synthetic control methods for comparative case studies: Estimating the effect of California's tobacco control program. Journal of the American Statistical Association, (490), 493505. https://doi.org/10.1198/jasa.2009.ap08746

Abadie, A., Alexis, D., \& Jens, H. (2015). Comparative politics and the synthetic control method. American Journal of Political Science, 59(2), 495-510. https://doi.org/10.1111/ajps.12116

Card, D., \& Alan, K. (1994). Minimum wages and employment: A case study of the fast food industry in New Jersey and Pennsylvania. The American Economic Review, 84, 772-793. https://doi.org/10.3386/w4509

Cerulli, G. (2019). A flexible synthetic control method for modelling policy evaluation. Economics Letters, 182, 40-44. https://doi.org/10.1016/j.econlet.2019.05.019

Liu, B. L., \& Wang, Y. (2018). Innovative performance promotion effect of free-trade zone: evidence from the quasi-experiment of the Shanghai Free-trade Zone. Research on Economics and Management, 39(9), 65-74.

Liu, R.-M., \& Zhao, R.-J. (2015). Western development: Growth drive or policy trap - An Analysis Based on PSMDID Method. No. 6, 32-43.

Yang, T. Y., \& Rong, Y. F. (2017). Does regional developing strategy promote economic growth? Evidence from revitalizing the northeast traditional industrial base. Economic Theory and Economic Management, (10), 8899.

\section{Copyrights}

Copyright for this article is retained by the author(s), with first publication rights granted to the journal.

This is an open-access article distributed under the terms and conditions of the Creative Commons Attribution license (http://creativecommons.org/licenses/by/4.0/). 